\title{
How semantic deficits in schizotypy help understand language and thought disorders in schizophrenia: a systematic and integrative review
}

\author{
Como déficits semânticos na esquizotipia auxiliam a compreender transtornos \\ da linguagem e do pensamento na esquizofrenia: \\ uma revisão sistemática e integrativa
}

Hélio Anderson Tonelli*

\begin{abstract}
Introduction: Disorders of thought are psychopathological phenomena commonly present in schizophrenia and seem to result from deficits of semantic processing. Schizotypal personality traits consist of tendencies to think and behave that are qualitatively similar to schizophrenia, with greater vulnerability to such disorder. This study reviewed the literature about semantic processing deficits in samples of individuals with schizotypal traits and discussed the impact of current knowledge upon the comprehension of schizophrenic thought disorders. Studies about the cognitive performance of healthy individuals with schizotypal traits help understand the semantic deficits underlying psychotic thought disorders with the advantage of avoiding confounding factors usually found in samples of individuals with schizophrenia, such as the use of antipsychotics and hospitalizations.

Methods: A search for articles published in Portuguese or English within the last 10 years on the databases MEDLINE, Web of Science, PsycInfo, LILACS and Biological Abstracts was conducted, using the keywords semantic processing, schizotypy and schizotypal personality disorder.

Results: The search retrieved 44 manuscripts, out of which 11 were firstly chosen. Seven manuscripts were additionally included after reading these papers.

Conclusion: The great majority of the included studies showed that schizotypal subjects might exhibit semantic processing deficits. They help clarify about the interfaces between cognitive, neurophysiological and neurochemical mechanisms underlying not only thought disorders, but also healthy human mind's creativity. Keywords: Schizotypal personality disorder, semantics, schizophrenic language, concept formation, schizophrenia.
\end{abstract}

\section{Resumo}

Introdução: Transtornos do pensamento são fenômenos psicopatológicos comumente presentes na esquizofrenia e parecem resultar de déficits do processamento semântico. Traços esquizotípicos de personalidade consistem de tendências de pensamento e comportamento qualitativamente semelhantes às observadas na esquizofrenia, além de uma maior vulnerabilidade para esse transtorno. O presente trabalho teve como objetivo revisar a literatura sobre déficits de processamento semântico em amostras de indivíduos com traços esquizotípicos, discutindo o impacto desse conjunto de conhecimentos sobre a compreensão dos transtornos de pensamento na esquizofrenia. Estudos sobre o desempenho cognitivo de indivíduos saudáveis que apresentam traços esquizotípicos são úteis na elucidação dos déficits semânticos subjacentes aos transtornos psicóticos do pensamento, com a vantagem adicional de evitar fatores confundidores normalmente presentes em amostras clínicas de indivíduos esquizofrênicos, tais como uso de antipsicóticos e hospitalizações.

Métodos: Foi realizada uma busca por artigos publicados em português ou inglês nos últimos 10 anos nas bases de dados MEDLINE, Web of Science, PsycINFO, LILACS e Biological Abstracts, utilizando-se as palavras-chave semantic processing, schizotypy e schizotypal personality disorder.

Resultados: A pesquisa resultou em 44 manuscritos, dos quais 11 foram inicialmente selecionados. A partir da leitura desses artigos, outros sete foram adicionalmente incluídos.

Conclusão: A grande maioria dos estudos incluídos mostrou que indivíduos esquizotípicos podem apresentar déficits de processamento semântico, auxiliando a compreender as interfaces cognitiva, neurofisiológica e neuroquímica subjacentes não só aos distúrbios pensamento, mas também à criatividade na mente humana saudável. Descritores: Transtorno esquizotípico de personalidade, semântica, transtornos da linguagem na esquizofrenia, formação de conceitos, esquizofrenia.

* Instituto de Psiquiatria do Paraná, Curitiba, PR, Brazil.

Financial support: none.

Submitted Nov 05 2013, accepted for publication Mar 20 2014. No conflicts of interest declared concerning the publication of this article.

Suggested citation: Tonelli HA. How semantic deficits in schizotypy help understand language and thought disorders in schizophrenia: a systematic and integrative review. Trends Psychiatry Psychother. 2014;36(2):75-88. http://dx.doi.org/10.1590/2237-6089-2013-0053 


\section{Introduction}

Schizophrenia is characterized by formal and content thought disorders. Formal thought disorders comprise loose associations or oblique ideas, which are frequently too abstract or concrete, and content disorders include delusional beliefs. Such psychopathological phenomena take place through language, which may be illogical or unintelligible as a consequence of tangentiality, overinclusive thinking, incoherence or delusions, and seem to result from deficits of semantic processing. ${ }^{1}$

The linguistic study of schizophrenic speech helps understand the cognitive processes underlying thought disorder and suggests that in schizophrenia the production of sentences prioritizes the meaning of words previously uttered (or, in more severe cases, just the sound of them), at the expense of context in which they should be inserted. 2,3 Delusions, in turn, might emerge from the allocation of inappropriate or idiosyncratic meaning to ordinary facts or events. ${ }^{4}$

Two theories about language abnormalities in schizophrenia shed light on the cognitive origins of thought disorders. ${ }^{5}$ One suggests that not only language disorders, but also thought disorders arise from problems affecting the structure and the function of semantic memory. In this theory, concepts, or semantic representations of words, are organized as nodes interconnected within a semantic network, in which related concepts (e.g., cat and dog) are situated near each other, and the activation of a node facilitates the activation of adjacent ones. ${ }^{1,5}$ Therefore, the activation of cat facilitates the recall of dog. In schizophrenia, there might be a hyperactivation of semantic networks, and distal concepts (e.g., cat and crocodile) may be abnormally associated, ${ }^{6}$ which might elicit spurious associations or unusual meanings.

The other theory suggests that impairments in working memory, which is commonly associated with the manipulation, selection, prioritization, and monitoring of semantic information, will eventually affect the production of language because it is processed in a manner that is divorced from context. ${ }^{5}$

Studies about the disorders of semantic processing in schizophrenia use several methods, the most common of which is semantic priming (SP). SP is a lexical decision test that examines the character of associations between mental concepts, given that it evaluates how easy it is to respond with a word (a semantic target) when it is preceded by a semantically related word (a semantic prime). For example, when asked to say the first word that comes to their mind after being exposed to the prime word cat, healthy individuals tend to answer dog; black is given as a response faster when preceded by the prime word white than by soft. Patients with schizophrenia, particularly those suffering from formal thought disorders, may respond with unusual primetarget associations, less driven by the direct meaning, because of putatively faster spreading of activation throughout their semantic networks, which may lead to the activation of distal concepts. ${ }^{1,5,6}$

The results of studies about SP in schizophrenia are, however, still contradictory, ${ }^{7,8}$ although this paradigm has improved greatly over the years. For example, there are differences between direct and indirect SP, which evaluate the relations between concepts. Accordingly, the concepts cat and cheese are indirectly connected by means of the concept mouse, ${ }^{1}$ which is, in turn, directly connected to cat.

SP has also been decoupled in automatic (implicit) and controlled (explicit) components based on speed of semantic processing. Automatic SP is faster, whereas controlled SP is slower and dependent upon working memory, expectation and semantic pairing. ${ }^{6}$ The use of electroencephalography (EEG) and functional neuroimaging techniques to examine individuals performing SP tasks has not only provided more precise scorings, but also detected several brain regions recruited by these tasks. ${ }^{6}$ Event related potential N400 is a component of the EEG characterized by a negative deflection peak occurring about 400 milliseconds after the onset of a stimulus loaded with meaning, such as words, signs, flavors or faces. ${ }^{6,9}$ Following a prime, a direct target, very close to the prime within the semantic network, usually triggers a waveform N400 of smaller amplitude or shorter negativity as a consequence of the reduction of expectancies. ${ }^{9}$ In this case, it is assumed that the prime stimulus plays the role of contextualizing the incoming information. On the contrary, little semantic association between prime and target stimuli, which are far from each other within the semantic network, in most cases results in $\mathrm{N} 400$ negativity. After being exposed to an indirectly or poorly associated prime-target pair, individuals with schizophrenia seem to need less time for the emergence of N400, and negativity is also reduced. ${ }^{10}$ This suggests that they might present faster spreading of the activation throughout the semantic network, in addition to insensitivity to semantic incongruity, or semantic illusion. ${ }^{6}$ Additionally, these features may also result from alterations of normal patterns of hemispheric contribution to language processing. ${ }^{11}$

Difficulties imposed by multiple variables that affect cognitive performance in patients with schizophrenia, such as use of antipsychotics, chronicity of illness, and psychiatric hospitalizations, ${ }^{1,6}$ may interfere with their performance on semantic tasks and add bias to the results of studies about semantic assignment and language among these individuals. 
Schizotypal personality traits consist of tendencies to think and behave that are qualitatively similar to schizophrenia ${ }^{12}$ and include cognitive or perceptual distortions, social and interpersonal deficits and eccentric behavior, as well as greater vulnerability to schizophrenia. ${ }^{13}$ These traits can be assessed using specific questionnaires and seem to present as a continuum in the general population. ${ }^{12}$ Studies about the cognitive performance of healthy individuals with prominent schizotypal traits help understand the semantic deficits underlying psychotic thought disorder with the advantage of avoiding confounding factors normally found in samples of individuals with schizophrenia.

This study conducted a systematic and critical review of the literature about semantic processing deficits in clinical and nonclinical samples of individuals with high schizotypy. It also discussed the impact of this knowledge upon the comprehension of schizophrenic thought disorder.

\section{Method}

In May 2013, full-text articles published in English or Portuguese in the previous 10 years, since May 2003, were retrieved from the databases MEDLINE, Web of Science, PsycInfo, LILACS and Biological Abstracts using the following Boolean phrases: semantic processing AND (schizotypy OR schizotypal personality disorder) (MEDLINE); and semantic processing AND schizotypy (Web of Science, PsycInfo, LILACS and Biological Abstracts). Studies should have an experimental design to evaluate the performance of clinical or nonclinical samples of individuals previously assessed for schizotypy in a variety of semantic processing tasks, such as simple lexical decision, detection of words in animations, assessment of typicality of words, and SP, with or without additional electroencephalographic assessment. The clinical samples included individuals receiving care in mental health services and diagnosed with schizotypy by trained mental health teams. Nonclinical populations included non-psychiatric individuals evaluated psychometrically for schizotypal traits. Studies with large samples and appropriate diagnostic and cognitive assessments were prioritized, i.e., those with sample sizes that favored statistical inference and were subsequently evaluated using established instruments for the assessment of schizotypy or schizotypal traits, as well as of other important traits, such as general psychopathology, proneness to delusions or psychotic thinking, cognition and laterality. Exclusion criteria: reviews, case reports and studies that did not include cognitive evaluation of patients with clinical or psychometric schizotypy to understand semantic processing. The initial search retrieved 44 titles, and 23 were selected as potentially eligible. After the exclusion of those found in more than one database, 17 remained, and 11 of them were included because they addressed the topic of interest directly. ${ }^{14-24}$ Seven studies were additionally included after reading those 11 full-text articles, ${ }^{25-31}$ and a total of 18 studies were included. Figure 1 summarizes the steps of study selection for this review.

\section{Results}

The studies included in this review used different methods and experimental designs to investigate language and semantic processing in schizotypy, such as lexical decision tasks, detection/identification of words, SP, divergent thinking and creativity and brain lateralization applied to populations with different degrees of schizotypy.

The vast majority of studies evaluated healthy subjects, often senior students, using instruments to measure schizotypy and propensity to delusional thoughts or hallucinations. Only one study used a structured interview to establish a diagnosis of schizotypal personality disorder. ${ }^{25}$ One study compared the performance of a community sample of individuals previously evaluated for schizotypal traits and a population of outpatients with schizophrenia using a task of creativity and divergent thinking ${ }^{31}$; one evaluated the effects of dopamine on the hemispheric processing of language ${ }^{27}$; and one, the effect of an antipsychotic agent on anomalous semantic activations. ${ }^{17}$

SP paradigm was used in nine of the selected studies, ${ }^{15-19,21,23,24,28}$ and five of them used the N400 potential. ${ }^{15-17,24,28}$ The authors of these articles addressed important variables of SP, shedding light on the dynamics of the activation of semantic networks. The use of the context when choosing words, a process that recruits working memory, has been studied by means of the $\mathrm{N} 400$ potential ${ }^{25}$ because its amplitude or its negativity is a measure of the ability to associate concepts properly, as well as primes and targets.

Stimulus onset asynchrony (SOA) defines the time elapsed between the presentation of a prime and the production of a target. ${ }^{10}$ Differences in SOA duration seem to characterize distinct types of semantic processing, such as automatic processing, with shorter SOA durations, and controlled processing, with longer SOA duration. Differences also depend on attentional processes and expectations ${ }^{18}$ and possibly discriminate inter-hemispheric function. Although it remains unclear whether automatic or controlled semantic processing is specifically impaired in schizophrenia, two manuscripts have focused on investigating it in schizotypy. ${ }^{18,24}$ 


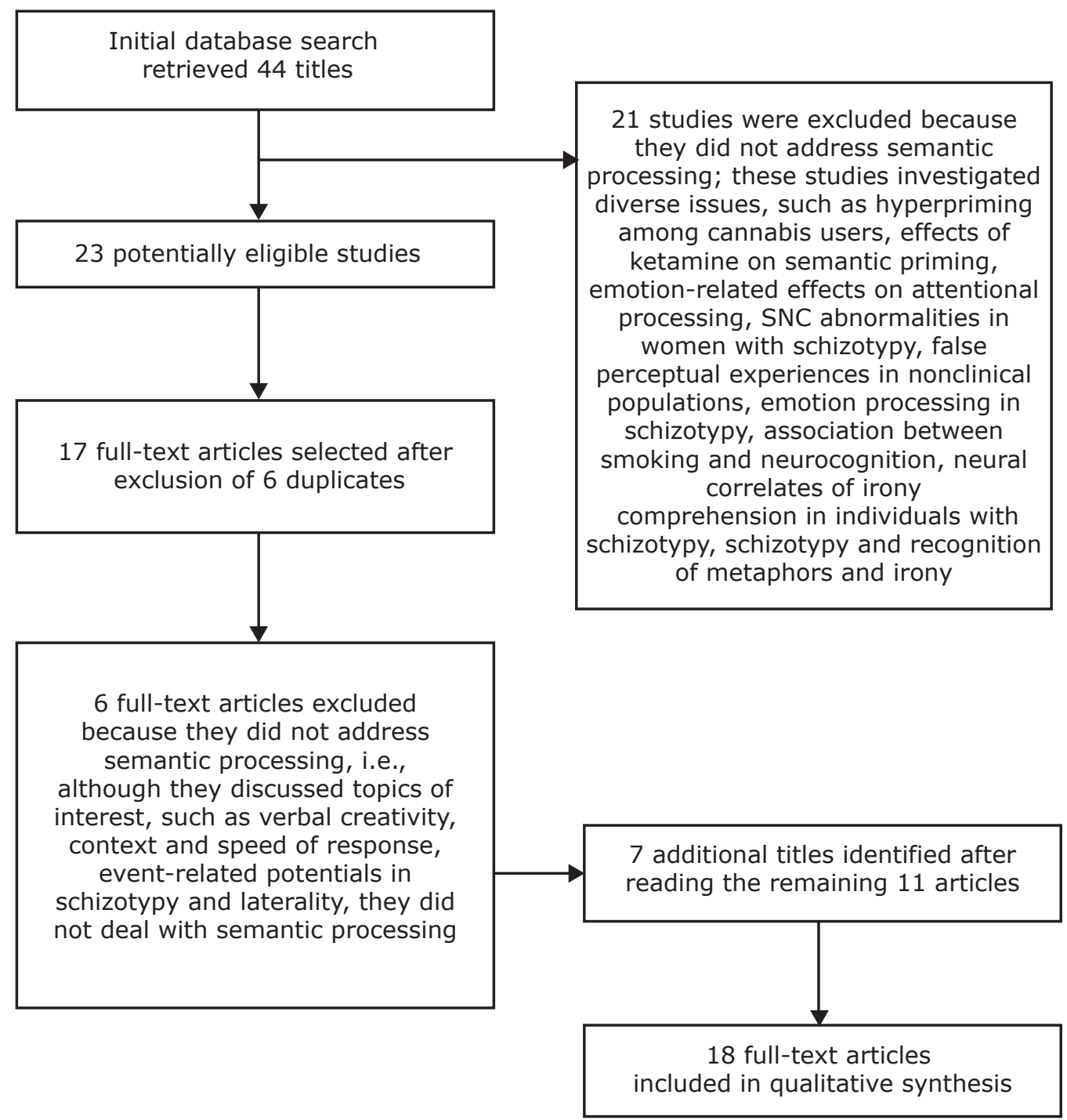

Figure 1 - Selection of full-text articles included in this review

SP may be further classified as direct or indirect depending on the type of associations: direct, as in cat and dog, or indirect, as in cat and cheese. Two manuscripts studied such SP processing categories ${ }^{14,19}$ and one ${ }^{23}$ studied negative SP, which might be considered a measure of semantic inhibition.

Some other variables of semantic processing are the capacity of semantic integration against disconfirmatory evidence, which ultimately reflects a measure of learning, and the effect of semantic compatibility, in which less time is required to access the compatibility of an expected target than to reject an incompatible one. Those variables were respectively examined by Prévost et al. ${ }^{28}$ and Kostova et al. ${ }^{21}$

Some studies investigated the role of cerebral lateralization in semantic discrimination, language and creativity in individuals with high schizotypy. ${ }^{21-23,29,31}$ Two of them used infrared spectroscopy to evaluate the association between schizotypy, language and brain lateralization. ${ }^{26,29}$

Table 1 summarizes the demographic characteristics of the populations, objectives, methods, instruments and main findings of each study.

\section{Discussion}

Most studies included in this review found that individuals with high scores on measures of schizotypy had impairments in semantic processing, ${ }^{14-17,19-31}$ but not all confirm the results of similar studies with individuals with schizophrenia. ${ }^{18}$ Nevertheless, the findings discussed here may contribute to the comprehension of the cognitive origin of disorders of thought and language in schizophrenia and of their complexity, because the populations examined were not exposed to the same confounding cognitive variables that usually affect patients with schizophrenia. 
Table 1 - Characteristics of the studies included in the review

\begin{tabular}{|c|c|c|c|c|}
\hline Manuscript & Population studied & Objectives & Methodology & Main findings \\
\hline $\begin{array}{l}\text { Niznikiewi-cz et } \\
\text { al., } 2004^{25}\end{array}$ & $\begin{array}{l}17 \text { right-handed women } \\
\text { diagnosed with schizotypal } \\
\text { personality disorder } \\
\text { according to DSM-III-R } \\
\text { (mean age: } 40.7 \text { years; } \\
\text { mean IQ: } 110 \text { ), and } 16 \\
\text { healthy women ( } 35.8 \\
\text { years; mean IQ: } 117.7 \text { ). } \\
\text { All native speakers of } \\
\text { English. }\end{array}$ & $\begin{array}{l}\text { To study the role of } \\
\text { context in semantic } \\
\text { processing in women } \\
\text { with schizotypy using } \\
\text { the paradigm of } \mathrm{N} 400 \\
\text { potential. }\end{array}$ & $\begin{array}{l}200 \text { sentences of } 5 \text { to } 8 \\
\text { words were presented } \\
\text { visually and auditorily to } \\
\text { the participants, who were } \\
\text { monitored using EEG. Half } \\
\text { of the sentences ended } \\
\text { with a word that fit the } \\
\text { context and the other half } \\
\text { ended with a word that } \\
\text { did not fit the context. } \\
\text { Participants should decide } \\
\text { on the meaning of each } \\
\text { sentence. }\end{array}$ & $\begin{array}{l}\text { N400 amplitudes } \\
\text { were more negative in } \\
\text { women with schizotypy, } \\
\text { a difference limited to } \\
\text { sentences with congruent } \\
\text { ends presented auditorily. }\end{array}$ \\
\hline $\begin{array}{l}\text { Folley \& Park, } \\
2005^{31}\end{array}$ & $\begin{array}{l}17 \text { outpatients with } \\
\text { schizophrenia ( } 29 \% \\
\text { female, mean age: } \\
39.5 \text { years), } 17 \text { healthy } \\
\text { controls ( } 47 \% \text { female, } \\
\text { mean age: } 35.2 \text { years) } \\
\text { and } 17 \text { individuals with } \\
\text { schizotypy ( } 47 \% \text { female, } \\
\text { mean age: } 22.8 \text { years), } \\
\text { recruited from the } \\
\text { community, } 10 \text { from each } \\
\text { group were evaluated with } \\
\text { spectroscopy. }\end{array}$ & $\begin{array}{l}\text { To assess whether } \\
\text { schizotypy is associated } \\
\text { with increased creativity } \\
\text { and to elucidate the } \\
\text { neural correlates of } \\
\text { divergent thinking using } \\
\text { infrared spectroscopy. }\end{array}$ & $\begin{array}{l}\text { After psychopathology, } \\
\text { schizotypy and intelligence } \\
\text { assessments, participants } \\
\text { performed creativity } \\
\text { tasks. }\end{array}$ & $\begin{array}{l}\text { High schizotypy was } \\
\text { associated with higher } \\
\text { divergent thinking, which } \\
\text { was additionally related } \\
\text { to the disorganization } \\
\text { dimension of schizotypy, } \\
\text { as well as bilateral } \\
\text { activity in the PFC. When } \\
\text { compared with the other } \\
\text { groups, individuals with } \\
\text { schizotypy recruited PFC } \\
\text { preferentially. }\end{array}$ \\
\hline $\begin{array}{l}\text { Kiang \& Kutas, } \\
2005^{16}\end{array}$ & $\begin{array}{l}24 \text { students, native } \\
\text { English speakers ( } 17 \\
\text { female, aged } 18 \text { to } 35 \\
\text { years). }\end{array}$ & $\begin{array}{l}\text { To study the association } \\
\text { between schizotypy and } \\
\text { the activation of semantic } \\
\text { networks using the SP } \\
\text { paradigm and N400 } \\
\text { potential. }\end{array}$ & $\begin{array}{l}\text { While monitored by EEG, } \\
\text { participants viewed terms } \\
\text { that defined a semantic } \\
\text { category followed by } \\
\text { high-typicality exemplars } \\
\text { (e.g., fruit/ apple), low- } \\
\text { typicality exemplars (e.g., } \\
\text { fruit/ cherry) or unrelated } \\
\text { words (e.g., fruit/clamp) } \\
\text { and were asked whether } \\
\text { the word was or was not } \\
\text { an exemplar of a given } \\
\text { category. }\end{array}$ & $\begin{array}{l}\text { Among all participants } \\
\text { N400 amplitude was more } \\
\text { negative for unrelated } \\
\text { terms and less negative } \\
\text { for high-typicality and } \\
\text { low-typicality exemplars. } \\
\text { The higher the schizotypy } \\
\text { score, the lower the } \\
\text { N400 amplitude to non- } \\
\text { exemplars, and the higher } \\
\text { the N400 amplitude both } \\
\text { to high- and low-typicality } \\
\text { exemplars. }\end{array}$ \\
\hline Mohr et al., $2005^{27}$ & $\begin{array}{l}40 \text { healthy right-handed } \\
\text { men, recruited from the } \\
\text { general population, with } \\
\text { a mean age of } 25 \text { years } \\
\text { and mean education of } \\
16.9 \pm 3.2 \text { years. }\end{array}$ & $\begin{array}{l}\text { To test the effects } \\
\text { of dopamine on the } \\
\text { hemispheric processing of } \\
\text { language using a simple } \\
\text { lexical decision test. }\end{array}$ & $\begin{array}{l}\text { Double-blind study; } \\
\text { participants received } \\
\text { levodopa or placebo } 30 \\
\text { minutes before undergoing } \\
\text { a lexical decision test. } \\
\text { This test consisted of } \\
\text { the presentation of pairs } \\
\text { of 4-letter sequences } \\
\text { alternately to their visual } \\
\text { fields. The sequences } \\
\text { were: word/non-word; } \\
\text { non-word/word, non-word/ } \\
\text { non-word). Participants } \\
\text { had to indicate whether } \\
\text { a meaningful word was } \\
\text { presented. }\end{array}$ & $\begin{array}{l}\text { The authors suggest } \\
\text { that in healthy brains } \\
\text { dopaminergic agonists } \\
\text { restore LH dominance for } \\
\text { language, by reducing RH } \\
\text { activity with respect to } \\
\text { positive schizotypal traits. }\end{array}$ \\
\hline $\begin{array}{l}\text { Tsakanikos \& } \\
\text { Reed, } 2005^{30}\end{array}$ & $\begin{array}{l}80 \text { students ( } 48 \text { women, } \\
\text { mean age: } 20.2 \text { years). }\end{array}$ & $\begin{array}{l}\text { To study event detection } \\
\text { bias using a word } \\
\text { detection paradigm in } \\
\text { short animations. }\end{array}$ & $\begin{array}{l}\text { Each participant received } \\
64 \text { trials of a continuous } \\
\text { sequence of brief } \\
\text { animated images, half of } \\
\text { which contained a word } \\
\text { hidden between non- } \\
\text { words, whereas the other } \\
\text { half contained only non- } \\
\text { words. They were asked } \\
\text { to ignore the non-words } \\
\text { and read aloud any words } \\
\text { they could see. }\end{array}$ & $\begin{array}{l}\text { Positive schizotypal traits } \\
\text { were associated with a } \\
\text { trend to report words } \\
\text { that did not appear in the } \\
\text { trials. }\end{array}$ \\
\hline
\end{tabular}




\begin{tabular}{lll}
\hline Kiang \& Kutas, & 60 students, native & To study the anomalous \\
$2006^{14}$ & English speakers (34 & production of language in \\
women, aged 18 to 35 & schizotypy by examining \\
years). & the typicality of responses \\
& to the Category Fluency \\
& Test (CFT), as well as \\
& the correlation between \\
& schizotypy and the total \\
& number of responses on \\
& the CFT.
\end{tabular}

Morgan et al., $2006^{18}$

Johnston et al., $2008^{19}$

Hori et al., $2008^{26}$
251 students, native English speakers; selection of 26 with high scores for schizotypy (20 women; mean age: 21 years), and 32 with low scores for schizotypy (13 women; mean age: 21 years).

54 students, native English speakers (41 women; mean age: 22.5 years).
To investigate alterations in SP in schizotypy and whether they may result from problems in automatic or controlled semantic processing, or in semantic storage. The authors also examined the association between different factors of schizotypy and deficits in SP.

To study semantic processing in schizotypy using direct and indirect SP and different SOA durations.
Participants were asked to generate as many names of fruits, fourfooted animals, articles of clothing and vehicles as they could within 1 minute. Correlations were analyzed between schizotypy and the probability of a typical first response, the typicality of responses and the number of responses on the CFT.

Related and non-related target-prime pairs along with pseudo-prime-target pairs of variable frequency were presented at a short (200ms) and a long SOA (750ms). Participants had to indicate whether a word was a real word or a non-word.

Performance on SP was measured by reaction times to prime-target pairs.

Participants initially grouped as high and low schizotypy were evaluated using infrared spectroscopy while performing tasks of word generation out of certain syllables (phonological verbal fluency) and semantic categories (semantic verbal fluency).
High scores in the SPQ (total and subscales) were significantly correlated with a lower chance of a first typical response, but only for the fruit category. High SPQ global scores and in the interpersonal and disorganization subscales were significantly correlated with more atypical responses, but also only in the fruit category. There was no significant association between schizotypy and the total number of responses on the CFT.

The group with high schizotypy showed higher scores on the PDI. Moreover, this group showed less priming at a short SOA. Individuals with low schizotypy had higher priming at long SOA. Priming effects in individuals with high schizotypy correlated positively to unusual experiences, but only at a long SOA.

There was a significant correlation between the cognitive disorganization subscale of the O-Life and indirect priming with total and shorter SOA durations. In the group of women, there were no significant correlations between cognitive disorganization and priming effect, whereas a robust correlation between cognitive disorganization and indirect priming with shorter SOA was found in the group of men.

Subjects with high scores on schizotypy showed greater activation of $\mathrm{RH}$ during phonological verbal fluency. The same association was not found for the semantic verbal fluency test. There was no association between schizotypy, laterality and typicality of responses in the semantic task. 
Hori et al., 2008 27 right-handed female volunteers (aged between 20 and 59 years), recruited from the general population were grouped into high $(n=14)$ and low schizotypy $(n=13)$.
To study the association between schizotypal traits and patterns of activation of the PFC during a verba fluency test using infrared spectroscopy.
Participants had to generate and verbalize words out of syllables provided by researchers.

Schizotypal traits in healthy women were associated with abnormal patterns of PFC activation during verbal fluency, but the number of words generated was not different in the 2 groups. Most strikingly, the group of women with high schizotypy had larger right PFC activation. The SPQ subscale of unusual perceptual experiences was associated with PFC activation during verbal fluency test.

Morgan et al., $2009^{20}$

Asai et al., 200922

students ( 33 women aged 18 to 21 years).

28 students (15 women; mean age: 19.7 years), native speakers of English. ow scores for schizotypy (13 women; mean age: 21 years) were selected for the study.

Kiang et al. $2010^{15}$

251 students, native high scores for schizotypy (20 women; mean age:
To study explicit semantic processing in individuals with high scores on schizotypy using an extensive battery of semantic tasks.

To study the association between schizotypy and brain lateralization in 2 separate experiments, one assessing motor performance and cerebral asymmetry, and the other, included in this review, assessing cerebral asymmetry and language through a go/no-go paradigm.

To study SP in schizotypy.
The authors evaluated the performance of individuals with high scores on a schizotypy dimension robustly associated with positive symptoms in 7 different measures of explicit semantic processing.

Participants received spoken stimuli, which consisted of real or ungrammatical words and were asked to press a button as quickly as possible only after hearing meaningful words.

The authors studied N400 amplitude elicited from individuals reading word pairs that were strongly or weakly associated, as well as not associated, at varying SOA durations (between 300 and 700 $\mathrm{ms}$ ).
Only one of the semantic processing measures, the semantic categorization, was significantly impaired in high schizotypy, particularly for lowfrequency words. Such deficits are most consistently associated with the cognitive disorganization subscale of the O-Life.

Positive schizotypal traits were associated with nonlateralization of semantic processing. Participants with high schizotypy also responded to semantic auditory stimuli with both hands and showed a strong ipsilateral effect.

Among all participants, N400 amplitudes to target words were higher for non-associated words and lower for strongly and weakly associated words. Higher SPQ total scores correlated significantly with lower indirect N400 priming effect at both SOA. Higher scores for cognitive-perceptual factors also correlated significantly with lower direct N400 priming effects at both $\mathrm{SOA}$, as well as lower indirect N400 priming effect at a $300 \mathrm{~ms}$ SOA. 
Grimshaw et al., $2010^{23}$

Prévost et al., $2010^{28}$

Kostova et al., $2011^{21}$

Debruille et al., $2013^{17}$
60 students selected from group of 300: 30 with high schizotypy (7 men; mean age: 18.6 ) and 30 with low schizotypy (10 men; mean age: 20 years), all native English speakers.
To study the resolution of semantic ambiguity in individuals with high and low schizotypy considering inter-hemispheric differences in semantic processing.
Individuals performed a test of semantic ambiguity, in which they had to indicate whether pairs of words were related or not. The first word (prime) was ambiguous (e.g., ball) and the second could be either related to the dominant sense of the prime (i.e., round) or to a subordinate meaning (e.g., dance). Response time was used as a measure of performance in the test. SOA was 750 ms because the authors believe that this interval may lead to major inter-hemispheric differences in SP.
To study the associations between N400 potential and schizotypy disorganization, proneness to delusions and interpersonal deficits using a semantic task.
First, participants were shown the words animal or inaction; after a SOA of $2 \mathrm{~s}$, distinct stimuli were presented. After that, individuals were asked to decide whether such targets corresponded or not to the animal category.

50 right-handed students, native speakers of French, aged 18 to 45 years ( 35 women).
To individualize $\mathrm{RH}$ and LH styles of semantic processing in a task of understanding pairs of auditory sentences presented binaurally.
Sentences were presented binaurally to individuals with high and low schizotypy. The last word of each sentence (the semantic target) was presented monaurally. Participants had to identify the semantic compatibility of the targets.

Double-blind study in which 2 groups of participants received $2.5 \mathrm{mg}$ of olanzapine or placebo, alternately, on 2 occasions, before performing semantic categorization tasks while N400 potential was recorded. SOA duration was $2 \mathrm{~s}$.
The group with low scores on the SPQ showed priming for dominant meanings and negative priming for subordinate meanings. The group with high schizotypy demonstrated priming for dominant meanings, but neither priming, nor negative priming for subordinate meanings. The authors suggest that the patterns of semantic ambiguity resolution found in the 2 groups reflect differences in interhemispheric participation in semantic processing, as the individuals in the high schizotypy group seem to activate the $\mathrm{RH}$ preferentially, whereas in the low schizotypy group, the LH. Or, alternatively, that there are deficits in inhibiting the $\mathrm{RH}$ in individuals in the high schizotypy group.

Potential N400 correlated significantly only with interpersonal and disorganization traits. The lack of correlation between N400 and positive traits suggests that the mechanisms of delusion-like belief formation on healthy individuals scoring high on SPQ might differ from those observed in schizophrenia.

Low schizotypy subjects exhibited a classic semantic compatibility effect in both hemispheres. High schizotypy subjects did not show right ear-LH semantic compatibility effect or right ear-LH activation of semantic memory, although their $\mathrm{RH}$ response was similar to that of individuals with low schizotypy.

In the placebo group, N400 had larger amplitude in high schizotypy. Olanzapine reduced N400 amplitude only in individuals with high schizotypy, an effect that did not depend on anxiety, mood, energy, or side effects of olanzapine. 


\begin{tabular}{|c|c|c|c|c|}
\hline $\begin{array}{l}\text { Wang et al., } \\
2013^{24}\end{array}$ & $\begin{array}{l}49 \text { individuals: } 17 \text { with } \\
\text { stable schizotypy ( } 10 \\
\text { women; mean age: } \\
21 \text { to } 24 \text { years), } 15 \text { with } \\
\text { unstable schizotypy ( } 8 \\
\text { women; mean age: } 20 \\
\text { years) and } 17 \text { with no } \\
\text { schizotypal traits (11 } \\
\text { women; age: } 20 \text { to } 47 \\
\text { years). }\end{array}$ & $\begin{array}{l}\text { To study the neural } \\
\text { components of semantic } \\
\text { processing in individuals } \\
\text { with schizotypy using } \\
\text { N400 potential and } \\
\text { differences between } \\
\text { implicit and explicit } \\
\text { semantic processing, and } \\
\text { to examine whether such } \\
\text { processing is stable or } \\
\text { may vary according to } \\
\text { schizotypy. }\end{array}$ & $\begin{array}{l}\text { SP tasks differed only in } \\
\text { the duration of the SOA: } \\
300 \mathrm{~ms} \text { in the implicit } \\
\text { task; } 700 \mathrm{~ms} \text { in the } \\
\text { explicit task. }\end{array}$ & $\begin{array}{l}\text { Individuals with } \\
\text { schizotypal traits } \\
\text { had normal implicit } \\
\text { semantic processing and } \\
\text { impairment on explicit } \\
\text { semantic processing. Such } \\
\text { impairments remained } \\
\text { stable despite variations } \\
\text { on schizotypy over time. }\end{array}$ \\
\hline
\end{tabular}

$\mathrm{EEG}=$ electroencephalography; $\mathrm{LH}=$ left hemisphere; $\mathrm{PFC}=$ prefrontal cortex; $\mathrm{RH}=$ right hemisphere; $\mathrm{SOA}=$ stimulus onset asynchrony; SP = semantic priming; $\mathrm{SPQ}=$ Schizotypal Personality Questionnaire.

Thought disorders are perceived by the clinician through impairments of verbal behavior, also called functional language disorders, which reflect high-level cognitive abnormalities in the production of thought ${ }^{2}$ and in the construction and updating of semantic representations. These disorders are distinguished from organic language disorders, such as dysarthria and dyslalia due to neurological diseases, which do not always include cognitive deficits. ${ }^{2}$ Although patients with schizophrenia and organic language disorders might exist, most of them have symptoms of thought and language secondary to syntactic and semantic distortions originating from problems in processing meanings and concepts..$^{2,3}$ These distortions appear to lie behind many of the formal peculiarities of psychotic thinking, as loose, overinclusive or idiosyncratic associative processes, in addition to unusual assignments of meanings that favor delusions. Just as individuals with schizophrenia, non-psychiatric populations with high scores for schizotypy seem to perform semantic tasks unsatisfactorily, with possible implications for their thought and language, although at a lower intensity.

\section{Semantic network activation and use of context in semantic processing}

The hypothesis of hyperactivation of semantic networks in schizotypy has been confirmed in some, but not all studies (Morgan et al. ${ }^{18}$ ). Kiang \& Kutas ${ }^{14}$ showed that, when instructed to generate words from a particular semantic category (fruit names), individuals with high scores on the SPQ provided more atypical responses, such as cherry, rather than typical ones, such as apple, which suggests that in these individuals more distal concepts within a semantic network are activated faster or more intensely than in controls. Likewise, when exposed to a SP where prime-target pairs characterized by typical terms (e.g., fruit - apple), atypical terms (e.g., fruit - cherry) and unrelated words (e.g., fruit - clamp), individuals with higher scores on the SPQ seem to notice more semantic relations in pairs of unrelated concepts, ${ }^{16}$ as demonstrated by the reduction in the negativity of the N400 potential after exposure to those pairs. Kiang et al. ${ }^{15}$ subsequently replicated these results and found that, similarly to what happens in schizophrenia, there is an association between schizotypy and lower N400 amplitude to unrelated concepts. This reduction in N400 negativity after exposure to unrelated prime-target pairs reflects an effect known as semantic illusion. ${ }^{6}$ Kiang et al. ${ }^{15}$ also found an association between the cognitive-perceptual domain of schizotypy and problems in the processing of directly related concepts, regardless of the SOA duration. Similarly, women with schizotypal personality disorder showed greater N400 amplitude after exposure to sentences with congruent ends than to sentences with incongruent ends, ${ }^{25}$ which suggests that they not only attributed meaning to what had no meaning, but also did not realize the meaning of trivial concepts. Sexual dimorphism is common in the course, prevalence and psychopathological expression of schizophrenia and mood disorders ${ }^{32}$ and something similar seems to happen regarding the processes underlining the assignment of meanings in schizotypy: cognitive disorganization seems to affect semantic processing more prominently in men than in women with marked schizotypal traits. ${ }^{19}$ Hori et al. ${ }^{29}$ studied a population of healthy women using a task of word generation out of letters and found greater activation of the right hemisphere $(\mathrm{RH})$ in those with high scores on the subscale of unusual perceptual experiences of the Schizotypal Personality Questionnaire (SPQ), which implies a propensity to semantic deficits, as discussed below. Gender differences might also include distinct mechanisms underlying semantic dysfunctions in individuals with high scores on schizotypy scales.

Semantic impairments in schizophrenia spectrum disorders may be additionally interpreted as resulting from distortions in the use of context during allocation of meanings, failures in inhibiting unrelated concepts, and deficits in access and storage of information within semantic networks, which, ultimately, lead to a state of semantic ambiguity. For example, in English, the sentence "putting money in the bank" could mean "making a deposit in a financial institution" or "burying it by the riverside." The proper assignment of the meaning of bank depends on the context in which this word is used; 
therefore, the appropriate management of context leads to spontaneous and automatic understanding of the subtle differences of the meanings expressed by that sentence. Individuals scoring high for schizotypy seem to have impairments in the ability of figuring out the accurate meaning of sentences with even a low degree of semantic ambiguity, and may become anxious or perplexed with the uncertainty that such sentences might induce. Some authors suggest that these difficulties are associated with SOA duration, because variations of this time interval distinguish automatic semantic processing, which involves shorter SOA and possibly reflects the function of the left hemisphere (LH), and controlled semantic processing, which involves larger SOA intervals, recruits working memory and expectation circuits preferentially, and reflects $\mathrm{RH}$ activity. It remains unclear whether there are problems that specifically affect controlled or automatic semantic processing in schizophrenia, ${ }^{18}$ and the same seems to be the case in the studies about schizotypy reviewed here. For example, Morgan et al. ${ }^{18}$ described a reduction of implicit SP, with a shorter SOA of 200 ms, in subjects with high scores on O-Life, which suggests slower activation of the automatic semantic network. However, these authors also documented an association of greater priming effect and larger SOA (750ms) with higher scores for schizotypy, which suggests that SP distribution is bimodal and that inadequate semantic associations are associated with problems in explicit semantic processing and arise as a result of improper use of context. Similar results have been recently reported by Wang et al., ${ }^{24}$ who documented impairments of explicit semantic processing at SOA of $700 \mathrm{~ms}$ in individuals with high scores on the $\mathrm{SPQ}$, which confirms the hypothesis of misuse of context as a consequence of impairments in working memory, or, as discussed below, loss of the LH dominance for language.

N400 potentials may reflect the effort required to integrate unexpected semantic information into existing mental representations. ${ }^{28,33}$ Thus, healthy individuals have larger N400 amplitudes when stimuli are out of context because of their increased cognitive effort. However, similar to delusional individuals, people with schizotypy may establish inappropriate semantic associations more easily, which is suggested by their lower N400 negativity associated with unrelated prime-target pairs. Individuals scoring high on schizotypy lack accurate updating of their semantic representations, which may favor the emergence of delusional beliefs and be responsible for rigidity, characteristic of this type of belief. ${ }^{33}$ In contrast, Prevost et al. ${ }^{28}$ failed to find any associations between $\mathrm{N} 400$ variations and positive schizotypal traits in a semantic correlation task using a long SOA (2s). These authors also suggest that the mechanisms of proneness to delusions in individuals with schizotypy may be correlated to the cognitive disorganization dimension, where contextual aspects of information are not properly maintained in working memory, rather than to the psychotic dimension, in which a predisposition to experience the world in a peculiar and unusual way may impair the updating of semantic representations and favor delusions. The findings reported by Prévost et al. ${ }^{28}$ seem to diverge from those by Morgan et al. ${ }^{18}$ and Kiang et al., ${ }^{15}$ who described N400-related semantic distortions significantly associated with the O-Life item of unusual experiences ${ }^{18}$ and the cognitive-perceptual dimension of the SPQ, ${ }^{15}$ both assessing psychotic features of schizotypy. Nevertheless, Morgan et al. ${ }^{20}$ has recently reported that individuals with high schizotypy had alterations specifically associated with disorganization traits in the performance of a semantic task, which reinforced the hypothesis of misuse of context due to problems in working memory.

\section{The role of dopamine and other neurotransmitters in semantic processing}

Several cognitive models explain the development of delusions and formal thought disorders in schizophrenia spectrum disorders, many of them including the neurotransmitter dopamine and its role on the signal to noise ratio regulation in prefrontal cortical circuits. ${ }^{34}$ In healthy subjects, cognitive processing begins with the proper separation between relevant (signals) and irrelevant (noise) stimuli. Individuals with schizophrenia and their first degree relatives seem to experience increased noise during sustained cognition due to dysfunctions of neocortical microcircuits that, in addition to dopamine, involve glutamate and gammaaminobutyric acid (GABA) ${ }^{34}$ (Figure 2). To increase the contrast between signal and noise, dopamine maintains a balance of glutamatergic and GABAergic synaptic interactions through differential actions on type 1 and 2 dopaminergic receptors (D1 and D2). Post-synaptic D2 stimulation appears to trigger a state of alert and enhanced focus, ${ }^{34}$ which is important for the production of a sense of salience following prediction errors or disconfirmatory evidence, ${ }^{33}$ whereas D1 stimulation promotes a state of target representation and network stability, favoring a suitable semantic update. ${ }^{34}$ People with schizophrenia spectrum disorders usually experience anomalous feelings of salience to the environment, because ordinary stimuli (noise) make them recruit excessive and inadequate attention ${ }^{35}$ and are experienced as having new, extraordinary or unusual meanings. The neural mechanisms behind these states are complex and appear to result both from dopaminergic hyperactivity in D2 receptors, whose distribution is predominantly mesolimbic, and hypoactivity in D1 receptors, whose 


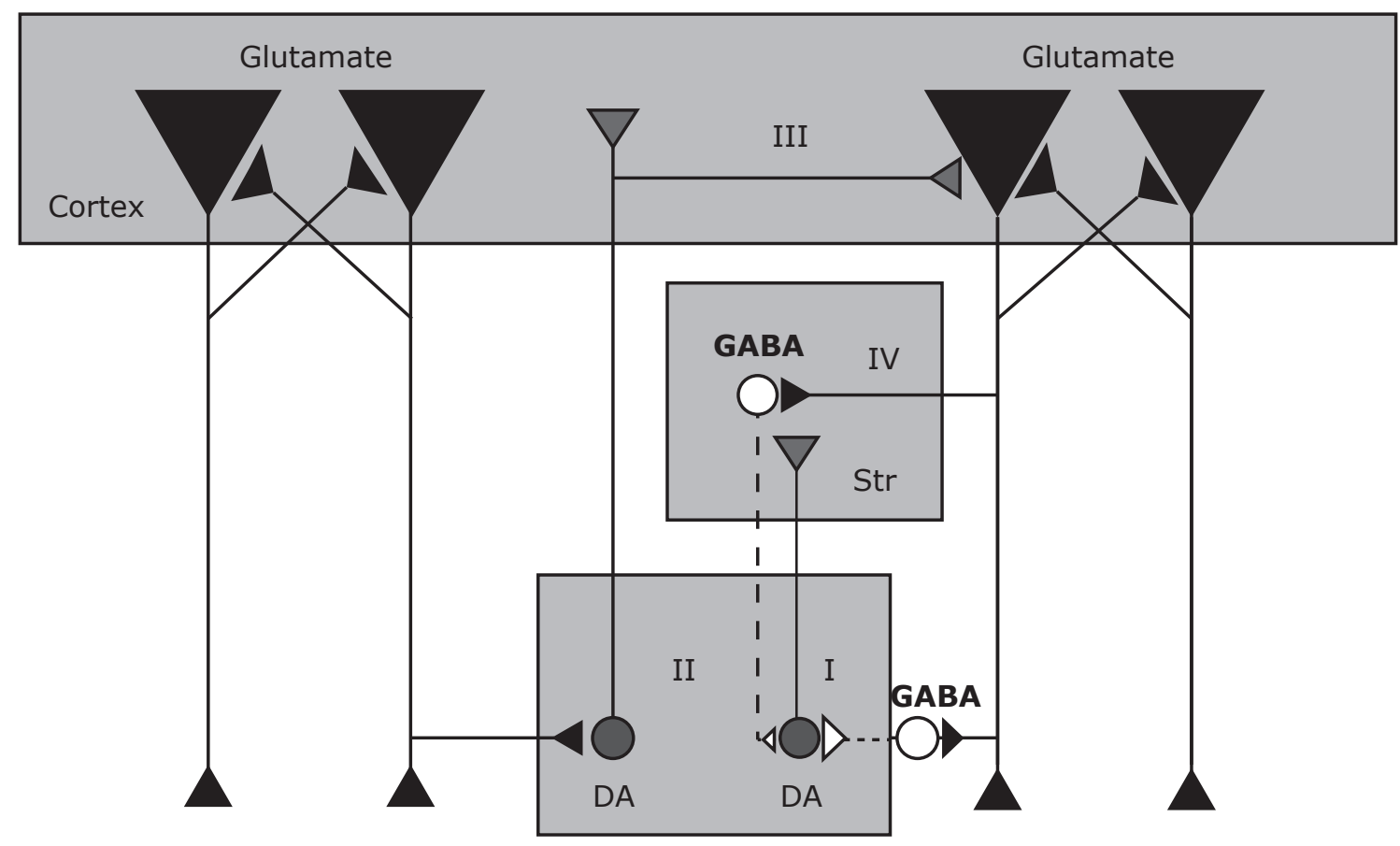

Figure 2 - Microcircuits associated with signal-to-noise ratio and semantic processing. These microcircuits include the neurotransmitters glumate, dopamine and GABA. Cortical glutamatergic pyramidal cells maintain reciprocal stimulatory connections (cell bodies in black; extrapyramidal glutamatergic pathway highlighted), which ensures a permanent excitatory state, critical to working memory. The activity of mesolimbic dopaminergic neurons (I) (cell bodies in gray) is associated with the generation of a state of alert, orientation and salience towards novel stimuli and appears to be mediated by D2 receptors. ${ }^{34}$ Mesocortical dopaminergic neurons (II) (cell bodies in gray), whose activity involves D1 receptors mainly, act to maintain a state of target representation and network stability, which leads to a proper semantic update. To achieve that state, mesocortical neurons indirectly control excessive mesolimbic activity and stimulate pyramidal cells (III) that, in turn, stimulate GABAergic cells (IV) (cell bodies in white), which ultimately inhibit mesolimbic neurons. ${ }^{38}$

Full lines stand for stimulatory activity, whereas dotted ones, for inhibitory activity. The diagram above is an oversimplification of a much more complex circuitry. DA = dopamine; Str = striatum; TVA = tegmental ventral area.

distribution is predominantly frontocortical. ${ }^{36,37}$ Thus, in schizophrenia, a frontocortical hypodopaminergic state may decrease the signal-to-noise ratio and destabilize or disinhibit the activation of semantic networks, facilitate remote associations and increase SP. Neurons of the mesocortical dopaminergic pathway regulate mesolimbic dopaminergic neurons indirectly through actions on glutamatergic and GABAergic neurons. ${ }^{38}$ Consequently, mesocortical hypodopaminergia may exacerbate the activity of mesolimbic neurons, which will enhance the focus on trivial stimuli. The role of dopamine in semantic processing is further supported by findings of a reduced priming effect on SP tasks and a reduction of anomalous semantic associations after treatment with levodopa. ${ }^{27}$ Furthermore, Mohr et al. ${ }^{27}$ suggest that dopamine modulates patterns of hemispheric dominance, which, when altered, might be associated with the emergence of psychotic symptoms. ${ }^{11}$

If delusions and disorganized speech in schizophrenia arise from problems in semantic processing, antipsychotics may be expected to have an effect on the performance of individuals with schizophrenia in semantic tasks. The only study addressing this question in schizotypy ${ }^{17}$ showed that the acute administration of small doses of olanzapine reduced N400 negativity only in individuals with high schizotypy, regardless of other mental states that might affect their cognitive performance, such as anxiety or depression. The authors of that study used a semantic categorization task and a SOA of $2 \mathrm{~s}$, which supports the hypothesis that, similar to what happens in schizophrenia, schizotypy is also associated with impaired explicit semantic processing and inappropriate use of context. At the same time, olanzapine actions may be better explained as resulting from an acute blockade of D2 receptors leading to a decrease of the firing rate of putatively hyperactive mesolimbic neurons, than as a consequence of normalization of a frontocortical hypodopaminergic state, which may only occur after chronic administration of this antipsychotic. ${ }^{39}$ Further studies about the effects of chronic treatments with antipsychotics on semantic tasks may help clarify whether these agents restore appropriate performance in semantic tasks by improving frontocortical dopaminergic transmission. 


\section{Jumping to conclusions and disorders of self-monitoring leading to semantic impairments}

Positive schizotypal traits may favor semantic distortions by other cognitive mechanisms well described in the literature about schizophrenia, such as jumping to conclusions and disorders of self-monitoring. Patients with schizophrenia seem to require less information to reach a conclusion, and are inclined to interpret an internally generated experience as a true sensory experience. This mechanism, described as disruptions on corollary discharge circuits, ${ }^{40}$ is an original framework to explain auditory hallucinations. Tsakanikos et al. ${ }^{30}$ found that individuals with schizotypy tended to perceive more non-words than words in a visual word discrimination task. Similarly to what occurs in schizophrenia, these deficits might derive from a tendency to reach a semantic conclusion quickly, or from disorders in separating an externally generated semantic stimulus and a mental representation of a semantic expectation. Although the mechanisms described above are usually restricted to explaining particular psychotic features, such as auditory hallucinations and passivity phenomena, they might actually have a supramodal character and an even more marked effect on the production of thought, given that an important accomplishment of the human mind is the permanent comparison between internally and externally generated information.

\section{Brain lateralization and semantic processing}

Studies correlating semantic processing to brain lateralization in schizotypy also shed light on the origins of psychotic thinking. In his seminal work, Crow ${ }^{11}$ suggested, almost two decades ago, that psychosis arises from a rupture of bi-hemispheric coordination of language, in which the dominant hemisphere processes syntactic and phonological aspects of language while the non-dominant hemisphere deals with semantics. Symptoms of thought arise when there is a loss of LH dominance, which may increase the effects of $\mathrm{RH}$ function. According to philosopher Daniel Dennett, ${ }^{41}$ the brain is commonly understood as a semantic machine, as it extracts meanings out of the information conveyed by the sense organs. ${ }^{41}$ However, still according to Dennett, the brain processes elements that act upon physics and chemistry laws, such as shapes and forces, which are actually syntactic variables. For Dennett, the brain is a syntactic machine doing semantic work, and the way that its hemispheres interact to perform their task of assigning meanings has been increasingly elucidated. For example, the processing styles of the hemispheres are diverse: immediate associations between concepts (e.g., cat and mouse) seem to be generated rapidly by the $\mathrm{LH}$, whereas indirect associations (such as cat and cheese), by the $\mathrm{RH} .{ }^{31}$ The $\mathrm{LH}$ seems to be predominantly activated by relevant meanings while inhibiting irrelevant ones. At the same time, the $\mathrm{RH}$, less sensitive to semantic violations, remains active for longer periods of time during semantic processing, ${ }^{21}$ and its effects consequently appear at larger SOA. Both hemispheres are capable of differentiating words from simple sequences of letters, but the LH is faster and more accurate in automatic lexical analyses, whereas the $\mathrm{RH}$ is specialized in subtler semantic ratings. ${ }^{27}$ Studies that investigated this aspect in schizotypy found a loss of the normal pattern of cerebral lateralization in various semantic tasks, which suggests that, as in schizophrenia, loss of LH dominance for language in schizotypy increases $\mathrm{RH}$ activity and promotes the emergence of remote associations that lead to the formation of delusions ${ }^{27}$ and other symptoms of thought disorder. At the same time, the increase of $\mathrm{RH}$ processing does not only predispose to psychotic symptoms, but possibly also to creativity. One of the processes underlying the theoretical superior creativity of some individuals with schizotypy is called divergent thinking, which implies the use of a flexible semantic judgment to redefine an existing idea and may be related to increased activity of the RH. Folley \& Park ${ }^{31}$ examined this possibility and found that individuals with schizotypy were prone to divergent thinking in different semantic tasks. In one of them, sequences of three words were shown to the participants, who were asked to find a fourth correlated word (e.g., blue, cake, cottage; possible answer: cheese). In another task, the participants had to describe uses for common and unusual objects after examining them. Schizotypy was associated with higher divergent thinking, and infra-red spectroscopy revealed that higher scores on the SPQ were related to preferential recruitment of the $\mathrm{RH}$ in solving these tasks. Two other studies used infrared spectroscopy to demonstrate that in schizotypy, just as in schizophrenia, there is greater activation of the $\mathrm{RH}$ in tasks of generating words out of letters or syllables, ${ }^{26,29}$ which usually activate the LH in normal individuals. The same effect was not found in tasks of word generation out of concepts, which recruit the $\mathrm{RH}$ even in healthy subjects.

Semantic ambiguity resolution tasks require the ability to discriminate words directly or indirectly related to an ambiguous prime (e.g., prime: ball; targets: round [direct], and dance [indirect]). Therefore, they might show that the $\mathrm{LH}$ is concerned with processing the direct target and the $\mathrm{RH}$, the indirect target. Grimshaw et al. $^{23}$ found that individuals with high schizotypy recruit mainly the $\mathrm{RH}$ to manage both dominant and subordinate meanings, in contrast to individuals with 
low schizotypy, whose dominant LH activity inhibits subordinate meanings (negative priming) and prioritize direct concepts. Consequently, the LH ensures that semantic information becomes attached to a context, so that mental representations are adequately updated. Context triggers previously stored mental representations of predictions, relations and regularities of the environment, and thus increases or decreases the chances of incorporating new information, depending on its contextual predictability or compatibility. ${ }^{12}$

Nevertheless, the similarities in the recruitment of cerebral hemispheres in semantic tasks in schizophrenia and schizotypy may be only superficial, as their underlying neurochemical mechanisms may be different. As mentioned above, dopamine plays a crucial role in semantic processing and possibly also in brain lateralization. Mohr et al. ${ }^{27}$ suggested that, similarly to patients with schizophrenia, individuals with high schizotypy may have greater right lateralization, and treatment with levodopa might increase this predisposition. Dopamine agonists elicit psychotic symptoms, and dopamine antagonists may act therapeutically by putatively reversing $\mathrm{RH}$ dominance. Interestingly, those authors found that levodopa did not exacerbate the asymmetry in schizotypal individuals, but attenuated it, which suggests that there might be differences between the dopaminergic regulation of interhemispheric semantic processing in schizotypy and schizophrenia.

\section{Conclusions}

In general, studies about semantic processing in healthy individuals with high scores for schizotypy are helpful in elucidating the origins of the formal and content disorders of thought in schizophrenia and have the advantage that participants are not exposed to the same confounding factors that affect cognition in individuals with schizophrenia.

These studies also describe the interfaces between cognitive, neurophysiological and neurochemical mechanisms underlying thought disorders in schizophrenia, as well as their involvement in the creativity of the healthy human mind. Crow ${ }^{11}$ suggested that individuals with schizophrenia have not been extinct by natural selection despite their reproductive disadvantage because their disorder, or, more likely, some factor associated with it, might bring some benefit to Homo sapiens. According to Crow, the answer to this paradox seems to lie in hemispheric specialization, which might have allowed the emergence of language, a skill that not only differentiated our cognition from that of other species, but also favored our many technological achievements. Actually, alterations in brain lateralization may have consequences in the way we understand the world, which seems to have, at one end of a spectrum, creative individuals that can assign a singular meaning to ordinary events of the world, and at the other end, profoundly sick individuals that, unable to merely realize the banality of such events, are constantly invaded by pathological feelings of novelty. The association of such mental states, as well as its cognitive, neurochemical and genetic factors, with schizophrenia remains to be determined. However, the findings reviewed here suggest that elucidating the dynamics of semantic networks and the interplay of brain hemispheres in the assignment of meaning and organization of language are promising questions for future studies of the physiopathology and treatment of psychotic conditions.

\section{References}

1. Spitzer M. A cognitive neuroscience view of schizophrenic thought disorder. Schizophr Bull. 1997;23:29-50.

2. Chaika E. A linguist looks at "schizophrenic" language. Brain Lang. 1974;1:257-76.

3. Covington MA, He C, Brown C, Naçi L, McClain JT, Fjordbak BS, et al. Schizophrenia and the structure of language: the linguist's view. Schizophr Res. 2005;77:85-98. Epub 2005 Apr 2.

4. Rossell SL, Batty RA, Hughes L. Impaired semantic memory in the formation and maintenance of delusions post-traumatic brain injury: a new cognitive model of delusions. Eur Arch Psychiatry Clin Neurosci. 2010;260:571-81. Epub 2010 Jan 30.

5. Kuperberg GR. Language in schizophrenia. Part 1: an introduction. Lang Linguist Compass. 2010;4:576-89.

6. Kuperberg GR. Building meaning in schizophrenia. Clin EEG Neurosci 2008;39: 99-102.

7. Pomarol-Clotet E, Oh TM, Laws KR, McKenna PJ. Semantic priming in schizophrenia: systematic review and meta-analysis. Br J Psychiatry. 2008;192:92-7.

8. Doughty OJ, Done DJ. Is semantic memory impaired in schizophrenia? A systematic review and meta-analysis of 91 studies. Cogn Neuropsychiatry. 2009;14:473-509.

9. Kutas M, Hillyard SA. Reading senseless sentences: brain potentials reflect semantic incongruity. Science. 1980;207:203-5.

10. Mohammad OM, DeLisi LE. N400 in schizophrenia patients. Curr Opin Psychiatry. 2013;26:196-207.

11. Crow TJ. Is schizophrenia the price that Homo sapiens pays for language? Schizophr Res. 1997;28:127-41.

12. Steel C, Hemley DR, Pickering AD. Associations between schizotypal personality traits and the facilitation and inhibition of the speed of contextually cued responses. Psychiatry Res. 2007;150:131-40. Epub 2007 Feb 6.

13. Tonelli HA. Cognição social no transtorno esquizotípico de personalidade e vulnerabilidade à psicose. In: Carvalho LF, Primi R. Perspectivas em psicologia dos transtornos da personalidade: implicações teóricas e práticas. São Paulo: Casa do Psicólogo; 2013.

14. Kiang M, Kutas M. Abnormal typicality of responses on a category fluency task in schizotypy. Psychiatry Res. 2006;145:119-26. Epub 2006 Oct 27.

15. Kiang M, Prugh J, Kutas M. An event-related brain potential study of schizotypal personality and associative semantic processing. Int J Psychophysiol. 2010;75:119-26. Epub 2009 Oct 8.

16. Kiang M, Kutas M. Association of schizotypy with semantic processing differences: an event-related brain potential study. Schizophr Res. 2005;77:329-42.

17. Debruille JB, Rodier M, Prévost M, Lionnet C, Molavi S. Effects of a small dose of olanzapine on healthy subjects according to their schizotypy: an ERP study using a semantic categorization and an oddball task. Eur Neuropsychopharmacol. 2013;23:339-50. Epub 2012 Jun 29.

18. Morgan C, Bedford N, Rossell SL. Evidence of semantic disorganisation using semantic priming in individuals with high schizotypy. Schizophr Res. 2006;84:272-80. Epub 2006 Mar 29. 
19. Johnston $A E$, Rossell $S L$, Gleeson JF. Evidence of semantic processing abnormalities in schizotypy using an indirect semantic priming task. J Nerv Ment Dis. 2008;196:694-701.

20. Morgan CJ, Bedford NJ, O'Regan A, Rossell SL. Is semantic processing impaired in individuals with high schizotypy? J Nerv Ment Dis. 2009;197:232-8.

21. Kostova M, de Loye $C$, Blanchet $A$. Left but not right hemisphere semantic processing abnormalities in language comprehension in subjects with schizotypy traits. Psychiatry Res. 2011;185:84-91. Epub 2010 Jun 8.

22. Asai T, Sugimori E, Tanno Y. Schizotypal personality traits and atypical lateralization in motor and language functions. Brain Cogn. 2009;71:26-37. Epub 2009 Apr 24.

23. Grimshaw GM, Bryson FM, Atchley RA, Humphrey MK. Semantic ambiguity resolution in positive schizotypy: a right hemisphere interpretation. Neuropsychology. 2010;24:130-8.

24. Wang K, Wang Y, Yan C, Wang YN, Cheung EF, Chan RC. Semantic processing impairment in individuals with schizotypal personality disorder features: a preliminary event-related potential study. Prog Neuropsychopharmacol Biol Psychiatry. 2013;40:93-102. Epub 2012 Aug 31.

25. Niznikiewicz MA, Friedman $M$, Shenton ME, Voglmaier $M$, Nestor PG, Frumin $M$, et al. Processing sentence context in women with schizotypal personality disorder: an ERP study. Psychophysiology. 2004; 41:367-71.

26. Hori $\mathrm{H}$, Ozeki $\mathrm{Y}$, Terada S, Kunugi H. Functional near-infrared spectroscopy reveals altered hemispheric laterality in relation to schizotypy during verbal fluency task. Prog Neuropsychopharmacol Biol Psychiatry. 2008;32:1944-51. Epub 2008 Oct 1.

27. Mohr C, Krummenacher $P$, Landis $T$, Sandor PS, Fathi $M$, Brugger P. Psychometric schizotypy modulates levodopa effects on lateralized lexical decision performance. J Psychiatr Res. 2005;39:241-50.

28. Prévost $M$, Rodier M, Renoult L, Kwann $Y$, Dionne-Dostie E, Chapleau I, et al. Schizotypal traits and N400 in healthy subjects. Psychophysiology. 2010;47:1047-56.

29. Hori H, Nagamine M, Soshi T, Okabe S, Kim Y, Kunugi H. Schizotypal traits in healthy women predict prefrontal activation patterns during a verbal fluency task: a near-infrared spectroscopy study. Neuropsychobiology. 2008;57:61-9. Epub 2008 May 2.

30. Tsakanikos E, Reed P. Seeing words that are not there: detection biases in schizotypy. Br J Clin Psychol. 2005;44:295-9.

31. Folley BS, Park S. Verbal creativity and schizotypal personality in relation to prefrontal hemispheric laterality: a behavioral and near-infrared optical imaging study. Schizophr Res. 2005;80:27182. Epub 2005 Aug 24.
32. Viveros MP, Mendrek A, Paus T, López-Rodríguez AB, Marco EM, Yehuda R, et al. A comparative, developmental, and clinical perspective of neurobehavioral sexual dimorphisms. Front Neurosci. 2012;6:84.

33. Corlett PR, Taylor JR, Wang XJ, Fletcher PC, Krystal JH. Toward a neurobiology of delusions. Prog Neurobiol. 2010;92:345-69. Epub 2010 Jun 15.

34. Winterer G, Weinberger DR. Genes, dopamine and cortical signalto-noise ratio in schizophrenia. Trends Neurosci. 2004;27:683-90.

35. Kapur S, Mizrahi R, Li M. From dopamine to salience to psychosis linking biology, pharmacology and phenomenology of psychosis. Schizophr Res. 2005;79:59-68.

36. Davis KL, Kahn RS, Ko G, Davidson M. Dopamine in schizophrenia: a review and reconceptualization. Am J Psychiatry. 1991; 148:1474-86.

37. Howes OD, Kapur S. The dopamine hypothesis of schizophrenia: version III - the final common pathway. Schizophr Bull. 2009;35:549-62. Epub 2009 Mar 26.

38. Laruelle M, Kegeles LS, Abi-Dargham A. Glutamate, dopamine, and schizophrenia: from pathophysiology to treatment. Ann N Y Acad Sci. 2003;1003:138-58.

39. Díaz-Mataix L, Scorza MC, Bortolozzi A, Toth M, Celada P, Artigas F. Involvement of $5-\mathrm{HT} 1 \mathrm{~A}$ receptors in prefrontal cortex in the modulation of dopaminergic activity: role in atypical antipsychotic action. J Neurosci. 2005;25:10831-43.

40. Gray DM. Failing to self-ascribe thought and motion: Towards a three-factor account of passivity symptoms in schizophrenia. Schizophr Res. 2014;152:28-32. Epub 2013 Jul 6.

41. Dennett DC. Intuition pumps and other tools for thinking. New York: WW Norton; 2013.

\section{Correspondence:}

Hélio Anderson Tonelli

Instituto de Psiquiatria do Paraná

Av. Candido de Abreu, 526, cj. 311, torre B, Centro Cívico

80530-905 - Curitiba, PR - Brazil

Tel./Fax: +55 (41) 3252.6988

E-mail: hatonelli@gmail.com 